\title{
eFest2018 Winner is Making Life More Colorful for Diabetics
}

\author{
James Beal (EIX.org | e-Fest ${ }^{\circledR}$ | FamilyBusiness.org)
}

KEYWORDS: Entrepreneurship, Startups, financing, Women, student entrepreneurs, efest2019, efest, Student innovators.

Meghan Sharkus of ExpressionMed, the eFest2018 grand prize winner, has made it her mission to make life more fun and fashionable for diabetics who must wear insulin devices every day. The colorful adhesive patches ExpressionMed makes to hold devices in place have gained a devoted following. At eFest2019 Sharkus, who won $\$ 100,000$ a year earlier in the competition, spoke with students about why she started her company, how eFest gave her a needed boost to overcome cash flow challenges and keep innovating, and the lasting benefits of collaborating with the other student entrepreneurs she met at eFest.

Additional Search Terms: medical devices, diabetes, finding investors, funding my company, attracting investment

To learn more about eFest, EIX's competition for undergraduate business ideas, click here (https://eix.org/e-fest-guide/)! 